\title{
PSICOPATOLOGIA E RELIGIOSIDADE NO LUGAR DO OUTRO: UMA ESCUTA LEVINASIANA
}

\author{
José Célio Freire
}

Virginia Moreira

\begin{abstract}
RESUMO. Este artigo visa recolocar a discussão da religiosidade de um ponto de vista psicopatológico, levando em conta não somente o sintoma moderno da ausência da fé, mas principalmente sua utilização como forma de preencher o lugar destinado ao outro na subjetividade. Nesta direção, deve-se levar em conta a presença singular do fenômeno da religiosidade na realidade brasileira, bem como sua incorporação nos quadros psicopatológicos, para que se possa adotar uma nova ótica desta relação.
\end{abstract}

Palavras-chave: religiosidade; psicopatologia; subjetividade.

\section{PSYCHOPATHOLOGY AND RELIGIOSITY IN THE OTHER'S PLACE: A LEVINASIAN LISTENING}

\begin{abstract}
This article aims to discuss religiosity from a psychopathological point of view. It takes into account not only the modern symptom or absence of faith, but especially how this is used as a way to fill the place destined to the other in subjectivity. In this direction, it is important to take into account the singular presence of the religiosity phenomenon in the Brazilian society and its incorporation in the psychopathological syndromes. That way it will be possible to adopt a new optic of this relationship.
\end{abstract}

Key words: religiosity; psychopathology; subjectivity.

\begin{abstract}
"Em vários momentos da sua terapia João mencionara a filha de quatro anos, a quem ele mais amava neste mundo, que lhe parecia ter comportamentos "estranhos", que preocupavam a ele e à mulher. Já tinha levado a menina a uma psicóloga, mas, na opinião dele, ela não tinha obtido nenhum resultado.

João conta que a filha tinha piorado das insônias e agora reclamava que não conseguia dormir por causa de um forte fedor que sentia perto de sua cama. A angústia da menina o deixara realmente assustado, nem ele nem a mulher sentiam nenhum cheiro diferente, mas a garota insistia desesperada em alguns momentos.

Depois de várias noites mal dormidas João decidiu seguir o conselho de uma comadre e levar a filha a um Centro Espírita. Apesar de ele não acreditar muito nestas coisas (João é médico, afinal de contas) tampouco desacredita, e já não sabia mais o que fazer
\end{abstract}

com aquela situação. No Centro lhe disseram que um espírito em um estado de deterioração muito adiantado permanecia junto da menina e indicaram um tratamento durante vários sábados seguidos.

João, meses depois, novamente mencionou a filha, agora aliviado, porque havia ficado "boa". O tratamento espiritual continuava e ele, mais que intrigado, estava mesmo era feliz, pois o que importava era ver sua filha dormindo tranqüila por toda a noite (...)" (Vinheta Clínica)

\section{INTRODUÇÃO}

A escuta clínica em psicoterapia e os atendimentos psiquiátricos e psicológicos no Brasil encontram-se povoados de Joãos. Trata-se de pessoas que, ao mesmo tempo em que buscam ajuda científica

* Psicólogo, Doutor em Psicologia, Professor Adjunto do Departamento de Psicologia e do Mestrado em Psicologia da Universidade Federal do Ceará, Brasil. Linha de pesquisa atual: Alteridade e Subjetividade.

\# Psicóloga, Doutora em Psicologia Clínica, Professora Visitante (Fulbright/Capes) no Programa de Pós-Doutorado em Medicina Antropológica no Medical School de Harvard University, USA, Professora Titular do Mestrado em Psicologia da Universidade de Fortaleza, Professora Colaboradora do Magíster en Psicología Clínica da Universidad de Santiago de Chile. 
- psicológica e médica - buscam também outras formas de ajuda, em especial a ajuda espiritual. Explicações científicas se entrelaçam com formulações místicas. Religiosidade e psicopatologia se superpõem de uma maneira tal que fica difícil identificar os limites entre uma e outra, onde termina a experiência psicopatológica e tem início a religiosidade, e vice-versa.

Neste artigo refletimos sobre esta questão utilizando-nos da ótica de Emanuel Lévinas para esboçar uma análise da psicopatologia e da religiosidade como ocupantes do lugar do outro. Discutiremos: 1) a ausência da fé como sintoma contemporâneo; 2) as dimensões antropológica e psicológica da religiosidade brasileira; 3) a religiosidade como sujeição ética e 4) a psicopatologia no lugar do outro em nós.

\section{DA AUSÊNCIA DA FÉ COMO SINTOMA}

Estudiosos do comportamento na contemporaneidade colocam que a falta de fé é um dos sintomas que caracterizam o mundo atual, o que estaria contribuindo para a etiologia dos crescentes quadros psicopatológicos, ligados a uma cultura marcada por uma ideologia individualista (Sloan, 1996; Schumaker, 2001). A falta de fé é colocada junto a outras características que descrevem o ser humano "pós-moderno", alvo de tipos de sofrimento psíquico como ansiedade vaga, impulsos para machucar a si mesmo e ao outro, a sensação de que nada vale a pena, o desejo de se drogar, hábitos maníacos de trabalho, aborrecimento com outras pessoas, fantasias com uma mudança radical no estilo de vida, estranhamento, alienação, dependência exagerada da opinião de outros, solidão, depressão (Sloan, 1996; Moreira, 2002).

A experiência da clinica psicológica e uma observação do comportamento do brasileiro na contemporaneidade mostram que todas as características acima relacionadas fazem parte da sintomatologia das diversas manifestações psicopatológicas com que nos deparamos cotidianamente no consultório (Costa, 2000a), ocorrendo, poderíamos pensar, uma "mundialização" ou "globalização" também dos sintomas, nos nossos dias. Mas não se pode dizer que a falta de fé caracteriza o brasileiro, na atual sociedade; muito pelo contrário, o Brasil vive um efervescente processo ligado à espiritualidade. Como acontece este processo? O que é que o caracteriza? Como a fé do brasileiro se vincula à psicopatologia, na cultura brasileira? $\mathrm{O}$ que é diferente, na contemporaneidade, na realidade brasileira e na de outras culturas, apesar dos processos de globalização que interferem na crescente fé brasileira quando o resto do Mundo Ocidental parece caminhar no sentido contrário?
Quais são as consequiências deste fenômeno para a psicopatologia? Quais suas implicações na prática clínica?

São muitas as questões que surgem em relação a esta temática no que diz respeito à especificidade da cultura brasileira. Neste artigo evidentemente não conseguiremos responder a elas, mas no propomos a avançar na compreensão deste fenômeno, cuja complexidade exige uma análise que transcenda a pura psicopatologia ou a pura religiosidade, resgatando a antropologia da cultura brasileira na interface com sua psicologia. Sem perder de vista a magnitude do problema, neste artigo nos propomos a utilizar o pensamento de Lévinas para intentar uma possível reflexão sobre como a psicopatologia e a religiosidade ocupam o lugar do outro na sociedade brasileira, marcada pelo individualismo que impregna, $a$ fortiori, o mundo ocidental como um todo.

Uma perspectiva histórica da psicopatologia mostra uma associação direta entre esta e a religião, a qual se torna aguda em alguns momentos históricos, como a Idade Média, onde sintomas psicopatológicos eram entendidos e tratados como manifestações de ordem espiritual, devendo ser combatidos pela religião. Não é o caso dos dias atuais, em plena era da tecnologia e da cientificidade, que implicam no desenvolvimento de uma determinada psiquiatria e psicologia. No entanto, tampouco se pode dizer que ocorreu uma separação definitiva entre psicopatologia e religião no Ocidente. Ao contrário, manifestações psicopatológicas continuam associadas, em maior ou menor escala, à religião, seja pelos efeitos de sua falta, através da falta de fé que impregna muitas das sociedades ocidentais atuais (Sloan, 1996), seja perpetuando o antigo modelo medieval, com uma interpretação mística das experiências que atualmente consideramos doença mental.Em ambos os casos a busca ou a rejeição da religião estaria vinculada a uma cultura individualista, geradora de um vazio, a ser preenchido seja pelo consumo seja pela religião.

Frei Betto (1997) nos mostra que este tipo de religiosidade opera de tal forma, em consonância com a sociedade de consumo, que uma religião privatizada passa a ligar diretamente o homem a Deus, sem passar pelo Outro. Ou seja, não é pelo respeito ou amor ao próximo, por exemplo, que se chega a Deus.

Estudos sobre a psicopatologia da depressão mostram que a crença e a prática da religião podem reduzir a manifestação desta doença (Shumaker, 2001). O assustador aumento desta patologia nas últimas décadas estaria, em parte, ligado ao desenvolvimento de uma mentalidade autônoma, ligada a uma forma de individualismo onde o homem é o centro do mundo (Moreira, 2001 e 2002). Por outro lado, se pode perceber uma "crise da 
religiosidade", seja pela extinção da fé em alguns países de Primeiro Mundo, analisada anteriormente, seja pela exacerbação de distintas formas de fé, como exemplificamos através da remissão a uma situação clínica que introduzimos neste artigo. Em ambos os casos, esta "crise da religiosidade" estaria contribuindo para a crise da saúde mental que aflige o Ocidente, em que "o progressivo desligamento dos seres humanos da totalidade, de uma visão cosmológica, já vinha sendo identificado desde a Idade Média, com práticas de isolamento e preocupação por si” (Silva 1999, p.8). Ou seja, o aumento da incidência de algumas manifestações psicopatológicas estaria vinculado ao decréscimo da religiosidade (Schumaker, 2001) ou aos seus usos e abusos, como se pode observar no Brasil de hoje em alguns segmentos sociais.

As formulações modernas ou tardo-modernas de religiosidade parecem acentuar os dispositivos individualizantes das práticas de si, remetendo o sujeito ao solipsismo religioso, onde se misturam, sem qualquer critério, práticas místicas, esotéricas, pseudoreligiosas e o mero ocultismo. Portanto, a crença numa religião não implica a religiosidade como dimensão ética, ou seja, do sagrado como o que não se pode deixar de cumprir - o respeito a Outrem. Mas a realidade brasileira nos mostra não só a proliferação de religiões mas também seu sincretismo.

Além do cristianismo, que engloba religiões de todos os matizes - ortodoxa, católica, protestante (luterana, metodista, presbiteriana, adventista, batista, anglicana), pentecostal e independente (Universal do Reino de Deus e Renascer em Cristo) - há ainda a profissão do budismo, do messianismo e de outros sistemas filosófico-religiosos orientais, dos mórmons e das testemunhas de Jeová, do fundamentalismo (islâmico e judaico), do espiritismo e dos cultos afrobrasileiros como a umbanda (e a derivação quimbanda ou macumba) e o candomblé. O mais especial disto tudo é que, no Brasil, várias práticas religiosas convivem pacificamente umas com as outras, quando não se misturam, numa fusão de cultos e doutrinas conhecido e estudado como sincretismo religioso, com influências do ocultismo e do islamismo. Há no Brasil, lado a lado, formas solitárias e coletivas de encontrar-se com Deus (ou com os deuses) e com todos os outros homens, de dar sentido à vida, de legitimar a organização social, de demarcar momentos importantes da vida social e individual, de organizar o mundo, enfim (DaMatta, 2000). A singularidade do caso brasileiro consiste em que essas crenças são suplementares, se complementando num formato pessoal de religiosidade onde o oficial e o popular se interpenetram. "O outro mundo tem muitas formas e são vários os caminhos de se chegar até ele no Brasil" (DaMatta, 2000, p.118).

\section{DA DIMENSÃO ANTROPO(PSICO)LÓGICA DA RELIGIOSIDADE BRASILEIRA}

Entendendo, não obstante, essa multiplicidade religiosa tipicamente brasileira como religiosidade, a literatura sociológica estuda a espiritualidade como característica marcante e fundamental da cultura do nosso país. Para Roberto DaMatta (1981), o mundo real é uma esfera que deve ser evitada o mais possível no universo social brasileiro, que tem como suporte três eixos: o lar, a rua e o sobrenatural. "Nestas esferas nós estamos lidando com santos, deuses e seres espirituais, que têm estado no nosso mundo e criam dúvidas sobre a exata realidade da sociedade em que vivemos. O mundo sobrenatural complementa, então, o mundo real (...)" (DaMatta, 1981, p. 253). No Brasil, não se pode dizer que a falta de fé ou a diminuição de religiosidade seria um dos fatores que contribuiriam para a constituição da psicopatologia na sociedade contemporânea, como acontece em outros países. Ao contrário, proliferam centros, seitas e credos de toda a ordem, que existem e se desenvolvem paralelamente, à margem da religião católica, a mais tradicional e de maior número de adeptos do país. Da mesma forma que existe no Brasil uma economia informal, se poderia dizer que existe também uma religião ou religiões informais que ocupam um lugar cada vez mais amplo na atual sociedade brasileira. É interessante notar, inclusive, que ainda que este seja um fenômeno quase maciço das classes sociais desprivilegiadas, ocorre também, e cada vez com maior freqüência, em todas as classes sociais. Quem sabe até como busca de respostas às angústias geradas por esta mesma sociedade promotora de patologias. $\mathrm{O}$ fato é que não é raro escutar de clientes em psicoterapia, em consultório particular, experiências ligadas à espiritualidade, como se pode observar no exemplo de João, apesar de que no Brasil, como diz Costa (2000b), "o mais comum é vermos pessoas que dizem possuir uma 'espiritualidade religiosa' 'selecionarem' o Deus adequado à situação adequada. Hoje é o Deus da tradição católica, amanhã é o Deus da tradição afro-brasileira..." (Costa, 2000b, p. 40).

A 'religiosidade' no Brasil é, sem dúvida, um campo vastíssimo para estudos antropológicos, sociológicos, psicológicos e, principalmente, psicopatológicos, dado que esta 'religiosidade' nos parece estar definitivamente amalgamada com a psicopatologia no imaginário do brasileiro. Este fato pode ser ilustrado através dos resultados de uma 
pesquisa transcultural sobre o significado das experiências de corpo, tempo e espaço em pacientes esquizofrênicos internados em hospitais psiquiátricos públicos no Brasil e no Chile (Moreira \& Coelho Jr., no prelo). Estes resultados mostram que o significado da experiência de corpo é atribuído somente à doença mental no Chile, enquanto no Brasil é freqüente que a vivência de alterações na corporeidade nos surtos esquizofrênicos seja atribuída à incorporação de espíritos relacionadas à umbanda e ao espiritismo. $\mathrm{Ou}$ seja, no Chile os pacientes entendem as alterações corporais sofridas como decorrentes da doença ou dos efeitos colaterais da medicação ingerida. No Brasil, os pacientes atribuem as alterações corporais experienciadas à incorporação de espíritos, ou fenômenos desta ordem, ainda que estejam submetidos ao tratamento psiquiátrico e hospitalizados, como os pacientes da amostra chilena. Mas, para os pacientes esquizofrênico-paranóides brasileiros, o significado da experiência sofrida no corpo é tanto da ordem da espiritualidade mística como de ordem médica. Estes resultados mostram a importância, para os profissionais de saúde mental no Brasil, de ter presente o significado ambíguo da vivência de doenças mentais. É importante respeitar estes pacientes, suas crenças, seus remédios, seus rituais de sabedoria da experiência popular (Nathan, 1999).

Concordamos com Costa (2000b) quando afirma que a presença do misticismo, do sobrenatural, das superstições e crendices é uma forma de resistência positiva e produtiva da população brasileira, através da insistência na introdução do "misterioso" no cerne da razão instrumental e calculista que caracteriza o mundo atual: "As perguntas e respostas que podem ser dadas pela ciência e pela tecnologia são magníficas, fascinantes, mas muita coisa está além ou ao lado da imaginação científica e tecnológica. Persistir acreditando em 'datas redondas', 'lobisomens', 'bruxas de todo gênero' é um sinal de vitalidade, de desobediência, de insubordinação contra as regras de aprisionamento de nossa imaginação, e não, apenas, como se pode pensar, sinal de limitação intelectual. $\mathrm{O}$ utilitarismo vulgar nos habituou a acreditar que só podemos ter interesse por aquilo que tem utilidade imediata, em termos de dinheiro, poder social, prazer sensorial. Ora, isso não é verdade" (Costa, 2000b, p. 53).

\section{DA RELIGIOSIDADE COMO SUJEIÇÃO ÉTICA}

Não obstante, como sugerimos mais atrás, há outra forma de conceber a religiosidade, a aproximação do sagrado ou a ligação com o Infinito. Este outramente religioso implica numa abertura para a alteridade do Outro e para o Infinito.
Antes de tratarmos da sobrevinda de Deus ao pensamento do homem, caberia uma rápida descrição da ética da alteridade radical de Emmanuel Lévinas (19061995) que, a partir de Husserl e de Heidegger, com aproximações e afastamentos importantes, e sob influência do pensamento de Rosenzweig e Buber, chega à proposição de uma ética da alteridade radical, que precede a própria ontologia e onde o Outro ocupa o lugar fundamental (Freire, 2002). O Outro aqui é o outro da alteridade, do diferente, do estranho. Lévinas nos alerta de que não somos donos de nossa própria casa, de que oferecemos à visitação do outro o que dele usurpamos, de que para com ele temos desde sempre uma dívida irresgatável. É esta dimensão - a da alteridade, em sua relação com a constituição da subjetividade - que nos interessa enfatizar neste momento. $\mathrm{O}$ Outro, o estrangeiro, sempre será estranho, mesmo aquele que habita dentro de nós mesmos - o outro (de mim ou de outrem). Ser sujeito, portanto, é já ser subjugado ao outro. Jugo do Outro que me obseda, que me persegue, que me intima, que me exige e que me domina.

A categoria central do pensamento levinasiano é o Rosto. O Rosto é visado, porém invisível; não se expressa, embora expresse a exterioridade, a alteridade radical, o Infinito; mas significa, no sentido de me reconduzir à minha realidade última, à responsabilidade por Outrem. Na relação que estabeleço com o Outro ele persiste absoluto, estranho, e me fala de sua Altura. Acolher o Rosto é inscrever-se na relação ética onde ele, Rosto, resiste a qualquer apreensão, mas não me violenta. No entanto, essa resistência ética do Outro é resistência a mim, pois posso querer matá-lo, aniquilá-lo, renunciar à sua compreensão. Mas querer não é ter de: o assassínio do Outro, se não é impossível - pois empiricamente um homem pode matar outro homem, na beligerância do crime e da guerra ou na ignomínia da tortura -, é o contrário da intimação do Não matarás. É o Rosto que permite o discurso original, aquele que obriga a entrar no discurso e o que possibilita a Razão, pois ele é a significação mesma, o Infinito que se apresenta em Outrem, essência da linguagem, que permitirá 'tematizar' as coisas do mundo. O Rosto apresenta o Outro na exigência de uma resposta, mas um terceiro (e toda a humanidade) nos observa e pela linguagem solicita a justiça dos iguais. Igualdade que se coloca na idéia de fraternidade.

Um ponto decisivo na elaboração levinasiana é o da afirmação de que o ético antecede o ontológico. Porém, ele fala não de um "dever ser" mas de um "ter de ser"; não da possibilidade de fazer escolhas, mas de uma disponibilidade de responder ao outro (responsabilidade) que antecede qualquer voluntarismo. Neste sentido, não há opção, não há decisão, só intimação pelo Outro. O Rosto não se apresenta à compreensão, 
é audição e palavra, escuta e discurso, portanto, consciência moral. O Outro sempre transborda e ultrapassa a minha compreensão, se constitui excesso de significação.

Esta abertura ao Outro, mesmo significando uma responsabilidade radical para com o próximo, não é fruto de uma intencionalidade, mas de uma sensibilidade onde o Eu deixa-se impactar pelo estranho, pelo externo, pela alteridade - e torna-se refém do Outro. A relação que aí se estabelece é assimétrica, apesar de permeada pela linguagem; é também diacrônica, pois remete tanto a um passado imemorial e irrecuperável quanto a um futuro que dista para além da morte. Resumindo, o para-ooutro se transforma em constituição do eu pelooutro, na subjetividade. Isso significa entender o outramente que ser - o ser para o outro - como fruto de uma obsessão do outro em mim, que constitui o psiquismo como reivindicação do Mesmo (do Mim) pelo outro - enquanto para si numa ingerência de fora para dentro. Esta subjetividade enquanto "se", que num primeiro momento é vulnerabilidade - sensibilidade e sensualidade -, torna-se, só posteriormente, intencionalidade. Contudo, esta subjetividade é a subjetividade de um sujeito desde sempre sujeitado, cuja obediência a outrem é anterior a qualquer ordem. É traumatismo sofrido por um sujeito refém de um outro em relação ao qual sua aproximação é já distância ética. Seu esforço de aproximação se torna possível no amor erótico, na fecundidade e na constituição de uma relação de paternidade e 'filialidade', por exemplo. Esses são alguns dos elementos centrais da "ética levinasiana", necessários para que entendamos a sua posição com relação à idéia de Deus e, assim, possamos fazer ilações para a dimensão psicopatológica da religiosidade.

O pensamento de Lévinas nos impõe esta evidência: Deus nos vem à idéia (Lévinas, 1992). Lévinas nos esclarece que a palavra Deus é uma palavra significante, independentemente do problema da existência de Deus. Aliada a isso, a idéia de Deus nos chega na forma cartesiana da "idéia-de-infinitoem-nós", cuja fenomenologia não se reduz a um ato de consciência 'tematizante' de um sujeito intencional. Neste sentido a idéia de Deus, em Lévinas, nada tem de teológica nem mesmo de teleológica. Diz respeito à idéia de Infinito, em sua anterioridade em relação à idéia de finito, e ao "des-inter-essamento" do ser pela pura passividade. Trata-se de uma responsabilidade, contudo, que não exige reciprocidade, pois a responsabilidade de outrem é coisa dele. É, porém, pelo rosto do outro que me chega o Infinito. "Deusvindo-à-idéia, como existência de Deus" (Lévinas, 1992, p.13), conclui Lévinas.

Na proximidade de Outrem se coloca esta espera de Deus, este temor pelo próximo que me coloca na condição de refém, cuja responsabilidade é ilimitada. Diz Lévinas que a teologia racional é vassala da filosofia ocidental, do pensamento do ser que torna Deus o ente por excelência. A transcendência é destruída. Assim, a filosofia é imanência mesmo, e não só conhecimento desta imanência. E sua interpretação de Deus se faz também em termos de imanência e presença (Lévinas, 1992).

Em Descartes, Lévinas irá buscar a noção de Infinito enquanto ruptura com a consciência, com a presença e com a representação. "A idéia de Deus, é Deus em mim, mas a partir de agora Deus rompendo a consciência que visa a idéias, diferindo de todo conteúdo" (Lévinas, 1992, p.105). A idéia de Infinito em nós não é uma tematização, mas uma não-indiferença do Infinito pelo pensamento incapaz de englobá-lo, ou seja, uma passividade "traumática" diante do Infinito. Lévinas se aproxima da questão da subjetividade a partir da idéia de Infinito. Esta não deve ser entendida, contudo, nem como teologia nem como teleologia. Também não se trata simplesmente da negação do finito pela idéia de Infinito, mas de a idéia de Infinito no pensamento ser anterior ao próprio finito que ela nega. Esta negação, segundo Lévinas, é a própria subjetividade do sujeito por trás da intencionalidade. Nas palavras dele, "A diferença entre o Infinito e o finito, é uma não-indiferença do Infinito com relação ao finito e ao segredo da subjetividade" (Lévinas, 1992, p.108). O pensamento não pode compreender - representar - o Infinito, pois esta é a incondição do pensamento.

E Deus, o que é? Para Lévinas é “outro que outrem”, uma alteridade prévia à alteridade de outrem - a transcendência verdadeira (Lévinas, 1992). Quando do frente-a-frente com o Outro resta dizer: eis-me aqui em nome de Deus. Não se trata de um diálogo, mas de um anúncio de paz e de responsabilidade absoluta (Lévinas, 1992). É o discurso profético da revolta ética no testemunho da responsabilidade enquanto pura obediência, onde não foi dada nenhuma ordem. Abre-se assim uma nova via para o psiquismo humano: a possibilidade de uma espiritualidade fundada na relação com o Tu e com o Deus invisível da invocação. "O movimento mesmo que conduz a outrem conduz a Deus" (Lévinas, 1992, p.227), conclui Lévinas peremptoriamente.

O sentido do humano estaria na responsabilidade irrecusável para com o outro, neste amor pelo outro que é, no limiar, Deus que vem à idéia - Revelação. Mas isso, sublinha Lévinas, nada tem a ver com uma "nova prova da existência de Deus", mas sim com a significância que 
a palavra Deus tem para o homem. Encontramo-nos no âmbito da ética, onde as noções de Infinito, de Absoluto e de Transcendência fazem sentido.

\section{POR UMA PSICOPATOLOGIA DO OUTRO EM NÓS}

Ora, esse breve incurso na obra levinasiana, notadamente a que trata da vinda de Deus ao pensamento - sejamos crentes, agnósticos ou ateus -, nos traz novos elementos para a discussão da religiosidade em sua relação com a psicopatologia. Não significa, para nós, simplesmente, que a ausência de religiosidade seja um sintoma contemporâneo. Ou que os distúrbios psiquiátricos que se expressam de forma corporal tenham por parte dos próprios doentes uma compreensão espiritual, mística ou o que o valha. Trata-se para nós, neste instante, de mostrar o preenchimento do lugar vacante do Outro (Freire, 2002) com um tipo de religiosidade que nada mais é do que uma forma alterada do cuidar de si, o que chamamos mais atrás de solipsismo religioso. A escuta ética de Emmanuel Lévinas (1992) é de extrema religiosidade, sem que para isso precise estar vinculada a qualquer religião ou igreja. $\mathrm{O}$ que conta aqui é a pertinência do Outro, sua injunção à minha pessoa e a centralidade da responsabilidade por ele como subjetividade mesma.

O tipo de sociedade em que vivemos incita-nos a uma atitude cada vez mais individualista, onde a responsabilidade por Outrem perde qualquer sentido para o sujeito. Se entendermos, a partir de Lévinas, a subjetividade como estruturada na e pela responsabilidade por Outrem, podemos fazer daí uma ilação para o psiquismo e sua desestruturação.

O mal-estar, o sofrimento humano, a psicopatologia enfim, mostra-se como uma decorrência do afastamento do sujeito daquilo que o constitui enquanto alteridade. $\mathrm{O}$ sujeito originariamente assujeitado, a serviço do Outro, em diaconia, ilude-se na busca de uma autonomia, de uma autoconsciência e de uma autocompreensão inviáveis. $\mathrm{O}$ adoecimento tem na ausência de religiosidade ou na sua exacerbação não o sintoma, mas a possibilidade mesma de sua emergência. Não ser (ou não se deixar ser) afetado pelo outro - o desafeto (Moreira \& Freire, 2003) leva à depressão bem como a outros transtornos psíquicos. Não se trata aqui de não crer em um Deus, mas de ter perdido a capacidade de ir em direção ao Outro. Trata-se de não ser capaz de assisti-lo na morte ou de dar-lhe o pão retirado da própria boca, para usarmos algumas formulações levinasianas.

\section{REFERÊNCIAS}

Betto, F. (1997) Crise da modernidade e espiritualidade. Em Nascimento, E. P. do (Sel.), Ética, (pp.15-36). Rio de Janeiro/Brasília, Garamond/Codeplan.

Costa, J. (2000a) Playdoier pelos irmãos. Em M. R. Kehl (Ed.), Função fraterna, (pp. 7-30). Rio de Janeiro: Relume Dumará.

Costa, J. (2000b) Entrevista com Jurandir Freire Costa. Em J. G. Couto (Ed.), Quatro autores em busca do Brasil, (pp.3155). Rio de Janeiro : Rocco.

DaMatta, R. (1981) The ethic of umbanda and the spirit of messianism: reflections of the Brazilian mode. Em T. Brunneau (Ed.), Authoritarianism capitalism, (pp.239-265) Colorado: Westview Pres

DaMatta, R. (2000) O que faz o brasil, Brasil? Rio de Janeiro, Rocco.

Freire, J. C. (2002) O lugar do Outro na modernidade tardia. São Paulo, Annablume.

Lévinas, E. (1992) De Dieu qui vient à l'idée. Paris, Librairie Philosophique J. Vrin.

Moreira, V. (2001). Más allá de la persona: hacia una psicoterapia fenomenológica mundana. Santiago: Editorial Universidad de Santiago de Chile.

Moreira, V. (2002). Psicopatologia critica (Parte II). Em V. Moreira \& T. Sloan, Personalidade, ideologia $e$ psicopatologia critica. São Paulo: Escuta.

Moreira, V. \& Coelho Jr., N. (no prelo) Phenomenology of the body, time and space in schizophrenia: a cross-cultural study Brazil-Chile. Terapia Psicologia.

Moreira, V. \& Freire, J. C. (2003) La dépression dans la postmodernité : un desordre des affections ou l'ordre des desaffections? Em B. Granger \& G. Charboneau, Phenomenlogie des sentiments corporels, (Vol. II, pp.111118). Paris: Le Cercle Hermeneutique.

Nathan, T. (1999) La influencia que cura. Buenos Aires: Fondo de Cultura Economica de Argentina.

Schumaker, J. (2001) Cultural cognition and depression. Em J. Schumaker \& T. Ward, Cultural cognition and psychopathology, (pp. 53-66). Westport: Praeger.

Silva, A.(1999) Elementos para compreender a modernidade do corpo numa sociedade racional. Caderno Cedes, 19 (48), 7-29.

Sloan, T. (1996) Damaged life: the crisis of the modern psyche. New York: Rotledge.

Endereço para correspondência: José Célio Freire, Av. da Universidade, 2762, Campus do Benfica, CEP 60.020-180, Fortaleza, Ceará, Brasil. E-mail: jcfreire@ufc.br 